\title{
Lateral-Expansion Pharyngoplasty: Combined Technique for the Treatment of Obstructive Sleep Apnea Syndrome
}

\author{
José Antonio Pinto ${ }^{10}$ Luciana Balester Mello de Godoy ${ }^{2}$ Heloisa dos Santos Sobreira Nunes 2,3 \\ Kelly Elia Abdo ${ }^{2,3}$ Gabriella Spinola Jahic ${ }^{2,3}$ André Freitas Cavallini ${ }^{2,3}$ Gabriel Santos Freitas ${ }^{2,3}$ \\ Davi Knoll Ribeiro ${ }^{2,3}$ Caue Duarte 2,3
}

\footnotetext{
${ }^{1}$ Director of Department of Otolaryngology, Núcleo de Otorrinolaringologia e Cirurgia de Cabeça e Pescoço de São Paulo, São Paulo, SP, Brazil

${ }^{2}$ Department of Otolaryngology, Núcleo de Otorrinolaringologia e Cirurgia de Cabeça e Pescoço de São Paulo, São Paulo, SP, Brazil

${ }^{3}$ Department of Otorhinolaryngology, Hospital Sao Camilo Pompeia, São Paulo, SP, Brazil
}

Int Arch Otorhinolaryngol 2020;24:e107-e111.
Address for correspondence José Antonio Pinto, Director of Department of Otolaryngology, Núcleo de Otorrinolaringologia e Cirurgia de Cabeça e Pescoço de São Paulo, São Paulo, SP, Brazil (e-mail: japorl@uol.com.br).

\begin{abstract}
Keywords

- obstructive sleep apnea

- polysomnography

- upper airway surgery

- surgical technique

- pharyngeal muscles

- pharynx/surgery

Introduction Obstructive sleep apnea syndrome (OSAS) is a multifactorial disease characterized by episodes of partial or complete collapse during sleep of different regions of the upper airway. Surgery for OSAS evolved with the introduction of different techniques, considering new surgical concept of reconstruction of the upper airway.

Objective To retrospectively evaluate the effectiveness of a new approach aimed at reducing pharyngeal collapse by combining two surgical techniques: lateral and expansion pharyngoplasty.

Methods We reviewed the medical records of 38 patients with OSAS undergoing lateral/expansion pharyngoplasty from January 2012 to December 2016. The following data were collected: patient age, gender, and pre- and postoperative body mass index (BMI), Epworth sleepiness scale (ESS) scores, snoring visual analogue scale (VAS) scores, and polysomnography (PSG) results.

Results The PSG results showed a significant reduction in the apnea/hypopnea index (AHI) from $22.4 \pm 27.3$ events/h preoperatively to $13.6 \pm 17.9$ events/h postoperatively $(p=0.009)$, with postoperative $\mathrm{AHI}$ reduction greater than $50 \%$ in $63.2 \%$ of the patients. There was also a significant reduction in the microarousal index $(19.5 \pm 22.6$ vs $11.0 \pm 13.4$ events/h; $p=0.001)$ and in the minimum oxygen saturation $(82.6 \pm 10.3$ vs $86.9 \pm 11.1 ; p=0.007)$. Conclusions Lateral-expansion pharyngoplasty represents a new surgical strategy for the treatment of OSAS in patients with palatal collapse by combining two different techniques: lateral and expansion pharyngoplasty. The two techniques, performed as a one-stage procedure, led to improvements in excessive daytime sleepiness, snoring, and PSG respiratory parameters by acting on lateral and retropalatal collapse, producing favorable results with good applicability in otolaryngology clinical practice.
\end{abstract}

received

February 24, 2019

accepted

June 19, 2019
DOI https://doi.org/

10.1055/s-0039-1695026. ISSN 1809-9777.
Copyright $(2020$ by Thieme Revinter

Publicações Ltda, Rio de Janeiro, Brazil
License terms

(ㄷ) (i) $\ominus$ (5) 


\section{Introduction}

Obstructive sleep apnea syndrome (OSAS) is a complex and multifactorial disease characterized by episodes of partial or complete collapse during sleep of different regions of the upper airway, such as nasal cavities, palate, uvula, tonsils, base of the tongue, lateral pharyngeal walls, and epiglottis. ${ }^{1}$ Continuous positive airway pressure (CPAP) has been long considered the first-line therapy for OSAS, being effective when used properly and in accordance with the standards of the American Academy of Sleep Medicine (AASM). ${ }^{2}$ However, due to difficult adherence of some patients to this treatment modality, the actual effectiveness of CPAP is low, with a large number of users abandoning it within 1 year of prescription. Conversely, surgery for OSAS does not depend on patient adherence, and when topodiagnosis is combined with the right pharyngeal procedure, effective long-term results have been observed. ${ }^{3}$

Surgical OSAS treatment has evolved over the years with the introduction of different techniques. In 1964, Ikematsu developed a surgical procedure to reduce snoring by shortening the palate and uvula. ${ }^{4,5}$ In 1977, Quesada et al introduced the concept of partial palate resection, a technique that was considered the first uvulopalatopharyngoplasty (UPPP). ${ }^{5,6}$ In 1981, Fujita et al published the UPPP technique by modifying the original procedure described by Ikematsu and generating great enthusiasm in the otolaryngology community. ${ }^{5,7}$ Several variations of the UPPP technique have been described since then, leading to a conceptual shift from aggressive palate resection to reconstructive surgery and improving pharyngeal function by changing its shape.

In 2003, Cahali described lateral pharyngoplasty, a surgical technique designed to splint the lateral pharyngeal walls via a microdissection of the superior pharyngeal constrictor muscle, thus giving support to these walls and reducing lateral collapse in patients with OSAS. ${ }^{5,8}$ In 2007, Pang and Woodson described expansion sphincter pharyngoplasty, which consists of a tonsillectomy followed by rotation of the palatopharyngeus muscle, partial uvulectomy, and closure of the anterior and posterior tonsillar pillars. ${ }^{1,5}$ The purpose of this procedure is to create lateral wall tension and remove the bulk of the lateral pharyngeal walls. In 2012, Sorrenti and Piccin improved the technique by stabilizing the palatopharyngeus muscle with a less aggressive and more physiologic surgery. ${ }^{5,9}$

Considering this new surgical concept of reconstruction of the upper airway, we combined two techniques, lateral and expansion pharyngoplasty, in a single procedure to both increase the pharyngeal space and address retropalatal and lateral collapse.

\section{Objective}

To retrospectively evaluate the effectiveness of a new approach aimed at reducing pharyngeal collapse by combining two surgical techniques: lateral-expansion pharyngoplasty.

\section{Methods}

This was a retrospective longitudinal study. The study was approved by the research ethics committee the institution, CAAE: 72825617.7.0000.0062-Comissão Nacional de Ética em Pesquisa (CONEP, in the Portuguese acronym). We retrospectively reviewed the medical records of all patients with OSAS undergoing lateral-expansion pharyngoplasty at the department of otolaryngology of our institution from January 2012 to December 2016.

The following data were collected from the medical records: patient age, gender, and pre- and postoperative body mass index (BMI), Epworth sleepiness scale (ESS) scores, snoring visual analogue scale (VAS) scores, and polysomnography (PSG) results.

The eligible participants were all patients aged 18 to 60 years old with a diagnosis of OSAS according to the International Classification of Sleep Disorders ${ }^{2}$ who were classified as Friedman stage I or II on physical examination and had retropalatal obstruction of the oropharynx and/or hypopharynx (Fujita type I and II) as seen with awake flexible endoscopy. Exclusion criteria were the presence of upper airway tumors and/or polyps, craniofacial anomalies, and hypertrophy of the base of the tongue as measured by cephalometry and fiberoptic nasopharyngoscopy with the Muller maneuver that grades hypopharyngeal and retropalatal collapse on a 4-point scale, excluding retroglossal collapse.

Obesity was defined as BMI $>30 \mathrm{~kg} / \mathrm{m}^{2}$. The severity of OSAS was classified according to the apnea/hypopnea index (AHI) as mild ( $\geq 5$ to $<15$ events/hour), moderate $(\geq 15$ to $<30$ events/hour), and severe ( $\geq 30$ events/hour) ${ }^{2}$. Postoperative evaluation was performed, on average, after 7 months of follow-up.

\section{Surgical Technique}

The procedure was performed under general anesthesia with orotracheal intubation. After performing a bilateral tonsillectomy, the superior pharyngeal constrictor muscle was dissected and sectioned (-Fig. 1). After the identification and elevation of the palatopharyngeus muscle, its

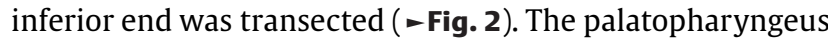
muscle was then fixed with 3.0 Vicryl suture, close to the ipsilateral hamulus of the pterygoid process, through a palatal tunnel ( - Fig. 3). The palatal mucosa was then closed with suture (-Fig. 4).

\section{Data Analysis}

Statistical analysis was performed using SPSS Statistics for Windows, version 21.0 (IBM Corp., Armonk, NY, USA). A pvalue $<0.05$ was considered significant for all analyses. Categorical variables were expressed as absolute and relative frequencies, and continuous variables were expressed as mean \pm standard deviation. Data were analyzed using the general linear model (GLM). For the longitudinal analysis, a generalized estimating equations (GEE) model was used to evaluate the treatment effect. The normality of data distribution was 

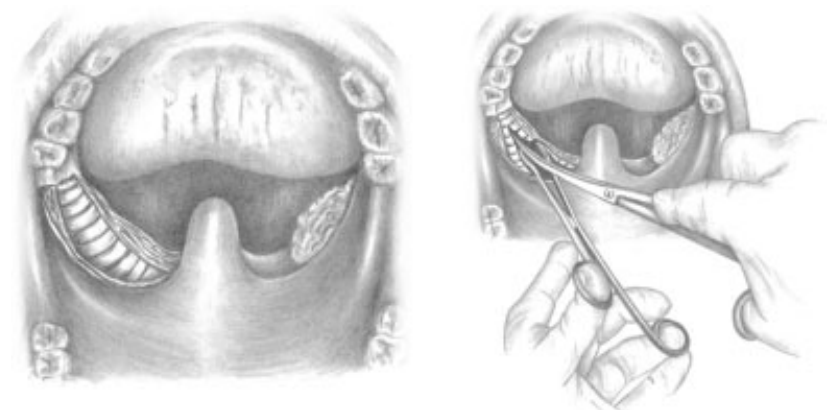

Fig. 1 Identification and dissection of the superior pharyngeal constrictor muscle.

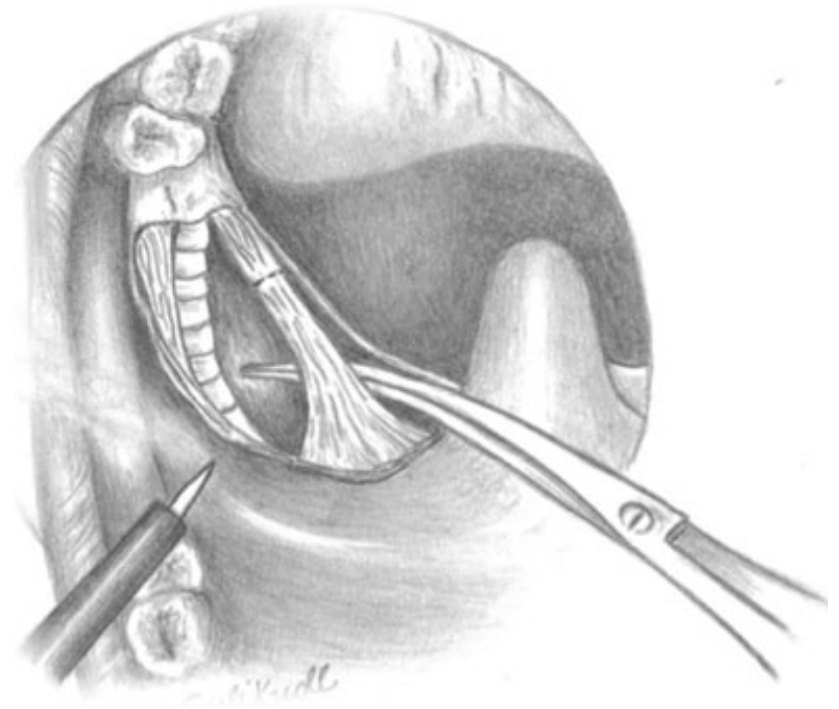

Fig. 2 The palatopharyngeus muscle is transected to obtain a tunnel through the palatal musculature that reaches the hamulus of the pterygoid process.
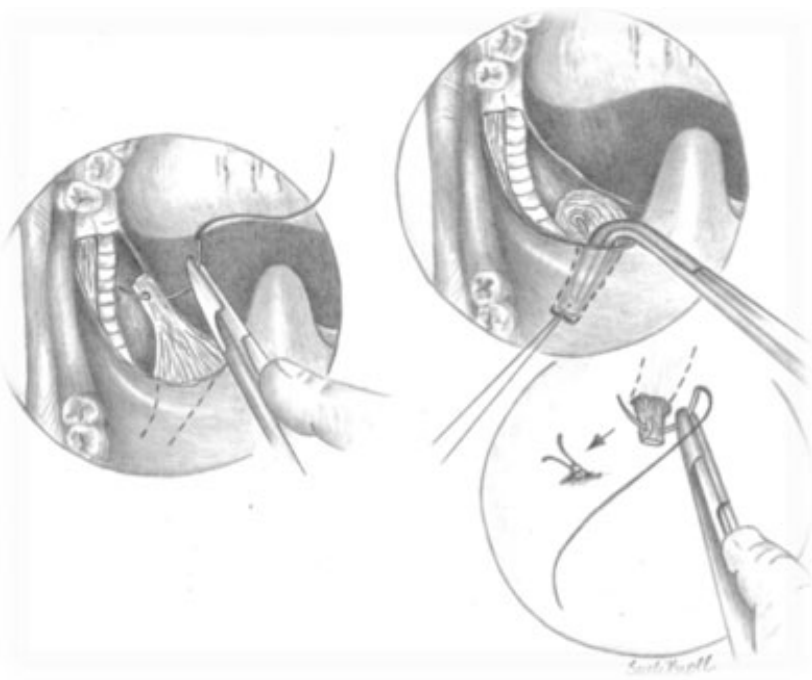

Fig. 3 The palatopharyngeus muscle flap is elevated through the palatal tunnel and fixed to the palatal musculature with 3.0 Vicryl suture, close to the ipsilateral hamulus of the pterygoid process.

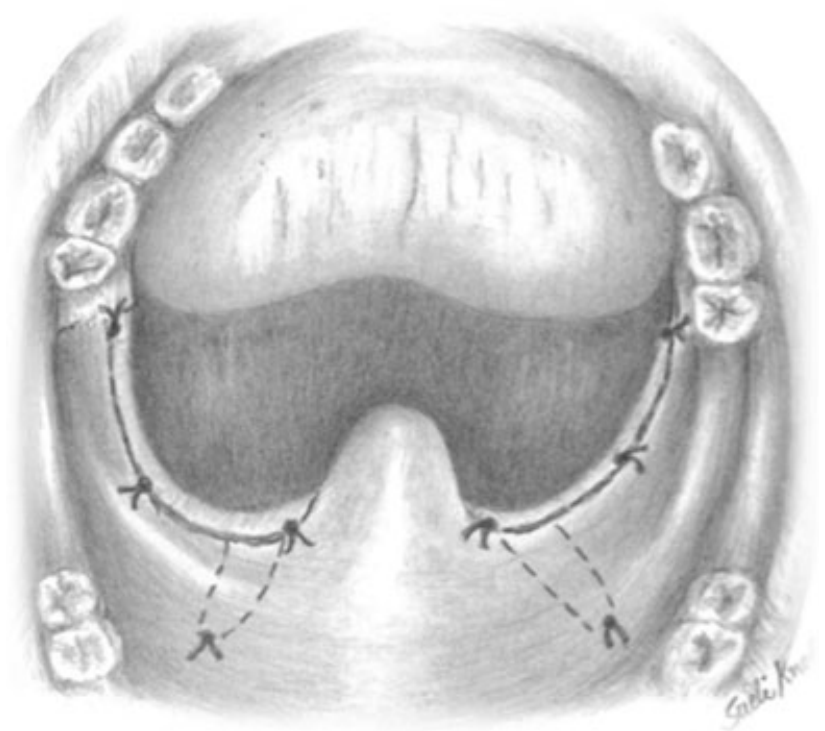

Fig. 4 Closure of the palatal mucosa with suture.

assessed by exploratory analysis of histograms or a comparison of Akaike and Bayesian information criteria. All ESS, snoring VAS and PSG variables were analyzed using gamma distribution. Age, gender, and delta BMI (baseline BMI postoperative BMI) were used as covariates. Bonferroni correction was applied to adjust for multiple comparisons.

\section{Results}

The sample consisted of 38 patients, 31 (81.6\%) men and 7 (18.4\%) women. The ages of the patients ranged from 30 to 58 years, with a mean age of $40.8 \pm 4.8$ years. The mean preoperative BMI was $27.4 \pm 2.8 \mathrm{~kg} / \mathrm{m}^{2}$, and the mean postoperative BMI was $26.6 \pm 5.8 \mathrm{~kg} / \mathrm{m}^{2}(p=0.4)$.

The mean ESS score significantly improved from $12.0 \pm 9.1$ preoperatively to $3.4 \pm 3.6$ postoperatively $(p<0.001)$. The mean snoring VAS score also significantly improved from $8.5 \pm 4.6$ preoperatively to $3.4 \pm 1.9$ postoperatively $(p<0.001)$.

The results of pre- and postoperative PSG are shown in -Table 1. Significant reductions were observed in postoperative AHI $(p=0.009)$, microarousal index $(p=0.001)$, and minimum oxygen saturation $(p=0.007)$ ( - Table 1$)$.

There was a postoperative $\mathrm{AHI}$ reduction greater than $50 \%$ in $24(63.2 \%)$ patients and of less than $50 \%$ in $8(21.0 \%)$ patients (-Table 2).

\section{Discussion}

Obstructive sleep apnea syndrome has received increased attention recently from the medical community due to its significant association with cardiovascular disease, hypertension, obesity, depression, dyslipidemia, gastroesophageal reflux disease, and diabetes mellitus, which can potentially increase health care expenditures. Sleep fragmentation and chronic hypoxia also affect patients' cognitive function and quality of life, leading to deficits in performance that may, in 
Table 1 Results of Pre- and Postoperative Polysomnography

\begin{tabular}{|l|l|l|l|}
\hline PSG variables & Preoperative & Postoperative & $p$ \\
\hline & Mean \pm SD & Mean \pm SD & \\
\hline $\begin{array}{l}\text { Sleep } \\
\text { efficiency (\%) }\end{array}$ & $85.5 \pm 12.8$ & $87 \pm 13.3$ & 0.4 \\
\hline $\begin{array}{l}\text { N1 Stage + N2 } \\
\text { Stage (\%) }\end{array}$ & $58.8 \pm 19.7$ & $55.8 \pm 19.1$ & 0.3 \\
\hline REM Stage (\%) & $21.2 \pm 12.1$ & $22.7 \pm 12.6$ & 0.4 \\
\hline $\begin{array}{l}\text { Microarousal } \\
\text { index (events/h) }\end{array}$ & $19.5 \pm 22.6$ & $11 \pm 13.4$ & 0.001 \\
\hline $\begin{array}{l}\text { Apnea/hypopnea } \\
\text { index (events/h) }\end{array}$ & $22.4 \pm 27.3$ & $13.6 \pm 17.9$ & 0.009 \\
\hline Mean SpO2 (\%) & $93.0 \pm 3.2$ & $93.9 \pm 3.3$ & 0.06 \\
\hline $\begin{array}{l}\text { Minimum } \\
\text { SpO2 (\%) }\end{array}$ & $82.6 \pm 10.3$ & $86.9 \pm 11.1$ & 0.007 \\
\hline$\% S p O 2<90 \%$ & $7.8 \pm 19.7$ & $12.5 \pm 25.1$ & 0.5 \\
\hline
\end{tabular}

Abbreviations: PSG, polysomnography; REM, rapid eye movement; SD, standard deviation; $\mathrm{SpO2}$, oxygen saturation as measured by pulse oximetry.

Table 2 Success of the postoperative apnea/hypopnea index $(n=38)$

\begin{tabular}{|l|}
\hline Decrease - apnea/hypopnea index $>50 \%: 24$ (63.2\%) \\
\hline Decrease - apnea/hypopnea index $<50 \%: 8(21.0 \%)$ \\
\hline Increase - apnea/hypopnea index: 6 (15.8\%) \\
\hline
\end{tabular}

turn, lead to increased risk of occupational and traffic accidents. $^{10,11}$

Currently, the first-line therapy for OSAS is CPAP, which has low adherence rates, with a large proportion of users abandoning the machine within 1 year of prescription. Such patients cannot be considered effectively treated. Surgery for OSAS, however, does not rely on any type of patient adherence, and when the right patient is matched to the right pharyngeal procedure, effective long-term results have been observed. Considering all patients with OSAS, it is known that overall treatment success rates are lower with surgery than with CPAP. For an effective comparison, adherence should be taken into account when investigating the impact of CPAP versus surgery on OSAS. Continuous positive airway pressure, an effective therapy with inconsistent adherence, can potentially be equivalent to surgery. ${ }^{3}$

Available medical and surgical treatment options, in their various modalities, are effective when performed according to OSAS topographic staging and severity; therefore, the choice of treatment continues to be a challenge for the treating physician. Recent innovations in techniques for the surgical treatment of OSAS remodel the narrow pharynx by advancing the soft palate and splinting the lateral pharyngeal wall, enlarging the lumen and reducing collapse. ${ }^{5}$ Palatal surgery yields better results when anatomic factors are involved. Neuromuscular collapsibility, however, often represents unpredictable results. Therefore, the main goal of innovative techniques is to reduce pharyngeal collapsibility. ${ }^{12}$
Cahali reported the effect of detaching the superior pharyngeal constrictor muscle on the reduction of laterolateral collapse. ${ }^{8}$ Expansion sphincter pharyngoplasty, described by Pang and Woodson and later modified by Sorrenti and Piccin, has shown positive results in retropalatal obstruction. ${ }^{1,9} \mathrm{~A}$ recent meta-analysis of anterior pharyngoplasty showed success in only $60.6 \%$ of patients, indicating the need for surgical procedures involving the lateral wall to improve the surgical outcome of patients with OSAS. ${ }^{13}$

To obtain better palatal expansion in patients with retropalatal and laterolateral collapse, we proposed the combined use of two techniques, lateral and expansion pharyngoplasty. Seven months after the surgery, patients who underwent the combined lateral-expansion pharyngoplasty approach achieved significant reduction in excessive daytime sleepiness and snoring as well as significant improvements in objective PSG measurements. There was a reduction in the $\mathrm{AHI}$ greater than $50 \%$ in $63.2 \%$ of cases, a success rate higher than that previously reported with the use of anterior pharyngoplasty alone. ${ }^{13}$ Also, there was a reduction in the $\mathrm{AHI}$ of less than $50 \%$ in $21 \%$ of cases, and an increase in the $\mathrm{AHI}$ in $15.8 \%$ of cases. In this respect, failure of the proposed surgical treatment could not be explained by the baseline BMI, weight gain during follow-up, or increased severity of symptoms or OSAS postoperatively. For this reason, we believe that there is a need for a more adequate assessment of hypopharyngeal collapse, with particular attention to the epiglottis and hypertrophy of the base of the tongue.

Extremely satisfactory results were obtained with the lateral-expansion pharyngoplasty in the present study. Also, sleep quality was positively influenced by surgery with possible beneficial effects on cognition, metabolism, and symptoms of excessive sleepiness. No major complications were observed; we found only transient odynophagia in a small proportion of patients. Taken together, our findings support the use of the combined lateral-expansion pharyngoplasty approach as a technique of good applicability in the practice of otolaryngologic surgery for OSAS when properly indicated.

As a limitation of this study, we have a small sample selected in a single institution. For a better evaluation, a multicenter study is required.

\section{Conclusion}

Lateral-expansion pharyngoplasty represents a new surgical strategy for the treatment of OSAS in patients with palatal collapse by combining two different techniques: lateral and expansion pharyngoplasty. The two techniques, performed as a one-stage procedure, led to improvements in excessive daytime sleepiness, snoring, and PSG respiratory parameters in patients with OSAS by acting on lateral and retropalatal collapse, producing favorable results with good applicability in otolaryngology clinical practice.

\section{Conflict of Interest}

The authors have no conflicts of interest to declare. 


\section{References}

1 Pang KP, Woodson BT. Expansion sphincter pharyngoplasty: a new technique for the treatment of obstructive sleep apnea. Otolaryngol Head Neck Surg 2007;137(01):110-114

2 Sateia MJ. International classification of sleep disorders-third edition: highlights and modifications. Chest 2014;146(05):1387-1394. Doi: 10.1378/chest.14-0970

3 Rotenberg BW, Vicini C, Pang EB, Pang KP. Reconsidering first-line treatment for obstructive sleep apnea: a systematic review of the literature. J Otolaryngol Head Neck Surg 2016;45(01):23. Doi: 10.1186/s40463-016-0136-4

4 T I. Study of snoring, 4th report: therapy. J Japan Oto-rhinoLaryngol. 1964;64:434-435

5 Pinto JA. Lessons from 50 Years of Uvulopalatopharyngoplasty. J Sleep Disord Ther 2016;5(03):3-5

6 Quesada P, Pedro Botet J, Fuentes EPE. Resección parcial del paladar blando como tratamiento del sindrome de hipersomnia y respiración peródica de los obesos. ORL Dips.:81-88.

7 Fujita S, Conway W, Zorick F, Roth T. Surgical correction of anatomic azbnormalities in obstructive sleep apnea syndrome: uvulopalatopharyngoplasty. Otolaryngol Head Neck Surg 1981; 89(06):923-934

8 Cahali MB. Lateral pharyngoplasty: a new treatment for obstructive sleep apnea hypopnea syndrome. Laryngoscope 2003;113 (11):1961-1968

9 Sorrenti G, Piccin O. Functional expansion pharyngoplasty in the treatment of obstructive sleep apnea. Laryngoscope 2013;123 (11):2905-2908

10 Lichtblau M, Bratton D, Giroud P, Weiler T, Bloch KE, Brack T. Risk of Sleepiness-Related Accidents in Switzerland: Results of an Online Sleep Apnea Risk Questionnaire and Awareness Campaigns. Front Med (Lausanne) 2017;4(April):34

11 Tarasiuk A, Reuveni H. The economic impact of obstructive sleep apnea. Curr Opin Pulm Med 2013;19(06):639-644

12 White DP. Advanced Concepts in the Pathophysiology of Obstructive Sleep Apnea. Adv Otorhinolaryngol 2017;80:7-16

13 Binar M, Karakoc O. Anterior Palatoplasty for Obstructive Sleep Apnea: A Systematic Review and Meta-analysis. Otolaryngol Head Neck Surg 2018;158(03):443-449 